\title{
Pulmonary transcriptomic responses indicate a dual role of inflammation in pneumonia development and viral clearance during 2009 pandemic influenza infection
}

\author{
Raquel Almansa ${ }^{1}$, Pamela Martínez-Orellana ${ }^{2}$, Lucía Rico ${ }^{1}$, Verónica Iglesias ${ }^{1}$, Alicia Ortega ${ }^{1}$, Beatriz

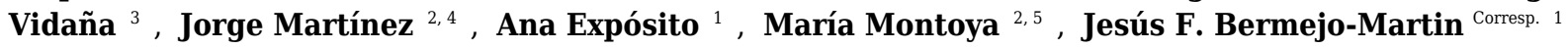 \\ ${ }^{1}$ Laboratory of Biomedical Research in Sepsis (BIOSEPSIS), Hospital Clínico Universitario de Valladolid - IECSCYL, Valladolid, Spain \\ 3 Pathology Department, Animal and Plant Health Agency (APHA), Surrey, United Kingdom \\ 4 Departament de Sanitat i Anatomia Animals, Universitat Autónoma de Barcelona, Barcelona, Spain \\ 5 African Swine Fever Virus Immunology group, The Pirbright Institute, Surrey, United Kingdom \\ Corresponding Author: Jesús F. Bermejo-Martin \\ Email address: jfbermejo@saludcastillayleon.es
}

Background: The interaction between influenza virus and the host response to infection clearly plays an important role in determining the outcome of infection. While much is known on the participation of inflammation on the pathogenesis of severe A (H1N1) pandemic 09-influenza virus, its role in the course of non-fatal pneumonia has not been fully addressed.

Methods: A systems biology approach was used to define gene expression profiles, histology and viral dynamics in the lungs of healthy immune-competent mice with pneumonia caused by a human influenza A (H1N1) pdm09 virus, which successfully resolved the infection.

Results: Viral infection activated a marked pro-inflammatory response at the lung level paralleling the emergence of histological changes. Cellular immune response and Cytokine Signaling were the two signaling pathway categories more representative of our analysis. This transcriptome response was associated to viral clearance, and its resolution was accompanied by resolution of histopathology.

Discussion: These findings suggest a dual role of pulmonary inflammation in viral clearance and development of pneumonia during non-fatal infection caused by the 2009 pandemic influenza virus. Understanding the dynamics of the host's transcriptomic and virological changes over the course of the infection caused by $\mathrm{A}(\mathrm{H} 1 \mathrm{~N} 1)$ pdm09 virus may help identifying the immune response profiles associated to an effective response against influenza virus. 
1 Pulmonary transcriptomic responses indicate a dual role of inflammation in pneumonia

4 Raquel Almansa ${ }^{a}$, Pamela Martínez-Orellana ${ }^{\mathrm{b}}$, Lucía Rico a , Verónica Iglesias a , Alicia Ortega a ,

5 Beatriz Vidaña ${ }^{c}$, Jorge Martínez ${ }^{\text {b,d }}$, Ana Expósito a , María Montoya ${ }^{\text {be }}$, Jesús F. Bermejo-Martin 6 a .

8 a Laboratory of Biomedical Research in Sepsis (BIOSEPSIS), Hospital Clínico Universitario de

9 Valladolid - IECSCYL, Valladolid, Spain.

10 b Centre de Recerca en Sanitat Animal (CReSA), Universitat Autónoma de Barcelona-IRTA,

11 Barcelona, Spain.

12 c Pathology Department, Animal and Plant Health Agency (APHA), Surrey, United Kingdom.

13 d Departament de Sanitat i Anatomia Animals, Universitat Autónoma de Barcelona,

14 Barcelona, Spain.

15 e African Swine Fever Virus Immunology group, The Pirbright Institute, Surrey, United 16 Kingdom.

18 Corresponding author: Jesús F Bermejo-Martin. Grupo de Investigación Clínica en Infección

19 Inmunidad y Genómica (ICIGEN), Hospital Clínico Universitario de Valladolid - IECSCYL, 20 Av. Ramón y Cajal, 3, 47003 Valladolid, Spain. E-mail address: 21 jfbermejo@saludcastillayleon.es. 


\section{Abstract}

24 Background: The interaction between influenza virus and the host response to infection clearly

25 plays an important role in determining the outcome of infection. While much is known on the

26 participation of inflammation on the pathogenesis of severe A (H1N1) pandemic 09-influenza

27 virus, its role in the course of non-fatal pneumonia has not been fully addressed.

28 Methods: A systems biology approach was used to define gene expression profiles, histology

29 and viral dynamics in the lungs of healthy immune-competent mice with pneumonia caused by a

30 human influenza A (H1N1) pdm09 virus, which successfully resolved the infection.

31 Results: Viral infection activated a marked pro-inflammatory response at the lung level

32 paralleling the emergence of histological changes. Cellular immune response and Cytokine

33 Signaling were the two signaling pathway categories more representative of our analysis. This

34 transcriptome response was associated to viral clearance, and its resolution was accompanied by

35 resolution of histopathology.

36 Discussion: These findings suggest a dual role of pulmonary inflammation in viral clearance and

37 development of pneumonia during non-fatal infection caused by the 2009 pandemic influenza

38 virus. Understanding the dynamics of the host's transcriptomic and virological changes over the

39 course of the infection caused by A (H1N1) pdm09 virus may help identifying the immune

40 response profiles associated to an effective response against influenza virus. 


\section{Introduction}

43 Influenza is one of the most common respiratory infectious diseases and a worldwide public

44 health concern. The World Health Organization (WHO) estimates that influenza viruses infect

45 around $5 \%-15 \%$ of the global population, resulting into 250,000 to 500,000 deaths each year.

46 (Vemula et al., 2016).

47 At the beginning of 2009, a new influenza virus of the subtype H1N1, [A (H1N1) pmd09], was

48 detected in Mexico. The vast majority of infections caused by this new strain were mild and self-

49 limiting upper respiratory tract illness. However, a small percentage of patients infected by the A

50 H1N1 pm09 virus developed primary viral pneumonia, resulting in respiratory failure, acute

51 respiratory distress, multi-organ failure and death (Health Protection Agency et al., 2009). A

52 large proportion of these severe cases occurred in young adults with accompanying co-

53 morbidities (chronic respiratory disease, cardiovascular disease, hypertension, obesity and

54 diabetes) (Jain et al., 2009).

55 The host response to the infection clearly plays an important role in determining the outcome of

56 the patients infected by influenza viruses (Almansa, Bermejo-Martín \& de Lejarazu Leonardo,

57 2012). In this regard, severely infected patients by the influenza A (H1N1) pdm09 virus was

58 characterized by the presence of high plasmatic levels of cytokines, chemokines and other

59 immune mediators accompanying the presence of pneumonic infiltrates (Bermejo-Martin et al.,

60 2009), (Hagau et al., 2010), (To et al., 2010). Moreover, we have shown that systemic levels of

61 these mediators were directly associated with viral levels secreted by the respiratory tract from

62 the beginning of the disease (Almansa et al., 2011a). In addition, persistence of viral secretion

63 has been found in the patients with the worst outcomes (Lee et al., 2009), paralleling the

64 presence of impaired expression of a number of genes participating in adaptive immune 
65 responses. Depression of adaptive immunity response has been previouslycorrelated with poor 66 control of infection and maintenance of inflammation, and secondarily with the generation of 67 damage to the infected tissues with the development of further respiratory failure (Bermejo68 Martin et al., 2010).

69 While much is known about the immune alterations and the participation of inflammation on the 70 pathogenesis of severe A (H1N1) pandemic influenza, their role in the course of non-fatal 71 pneumonia has not been sufficiently studied. Aimed to clarify this role, we employed a systems 72 biology approach to study gene expression profiles and its relation to histology and viral 73 dynamics in the lungs of healthy immune-competent mice with pneumonia caused by human 74 influenza A (H1N1) pdm09 virus, which successfully resolved the infection. 


\section{Material and methods}

\section{Ethics statement}

78 The ethical protocol and the research were reviewed and approved by the Animal and human

79 Experimentation Ethical Committee of the Autonomous University of Barcelona (Internal

80 Register Number 1124M2R) and the Ethical Animal Experimentation Commission of the

81 Catalan Government (Register Number: 5767).

82 All the animal experiments were done at the Biosafety level 3 (BSL3) facilities of the Centre de

83 Recerca en Sanitat Animal (CReSA, Barcelona, Spain). Animal care was performed according to

84 the standard procedures of the center (Martínez-Orellana et al., 2015). Seven weeks-old

85 C57BL6/JOlaHsd (C57BL6) female mice (Harlan Laboratories, Barcelona, Spain) were housed

86 in groups in experimental isolation cages for one week in acclimation (72 animals in total).

87 Throughout the experiment, all mice were provided with commercial food pellets and tap water 88 ad libitum.

89 A (H1N1) pdm 2009 Catalonian virus and mice infection.

90 A human pandemic Influenza A virus, A/Catalonia/63/2009 (CAT09) (GenBank accession

91 numbers GQ464405-GQ464411 and GQ168897) was used for animal infection (Busquets et al.,

92 2010). CAT09 was passaged in MDCK two times and the viral stock had a titer of

$93106 \mathrm{PFU} / \mathrm{ml}$. Animals were divided into two groups of 32 mice each; distribution was done as

94 follows: untreated control group (mock group) and pdmH1N1 2009 infected-group (CAT09). To

95 evaluate the pathogenicity mice were infected through intranasal instillation with $50 \mu \mathrm{L}$ CAT09

96 at $104 \mathrm{PFU} / \mathrm{mice}$ as described previously (Itoh et al., 2009). Successful CAT09 mice infection

97 and pathogenicity was previously confirmed by our experimental work (Orellana-Martínez, 
98 2014). Control non-infected mice were treated with $50 \mu \mathrm{L}$ phosphate-buffered saline (mock

99 infection) to reproduce CAT09 infection.

100 Mice monitoring and sampling

101 During ten days, mice were observed daily to record changes in body weight and clinical signs.

102 Based on our previous experimental work, the day showing the most important histological

103 changes in the lung following infection caused by CAT09 is day 5, while resolution of

104 histological changes occurs by day 10 . Consistently with our previous experience (Orellana-

105 Martínez, 2014), necropsies of 12 animals per group were performed at days 1, 5 and 10 post

106 infection (dpi). Animals were euthanized with intraperitoneal inoculation of penthobarbital under

107 anesthesia with 5\% isofluprane and tissue samples of lung were dissected from dead animals

108 using the standard surgical procedures. Lung samples of six animals per group were used for

109 viral load determination and histological examination. Lung samples were snap frozen on dry ice

110 and stored at $-80^{\circ} \mathrm{C}$ until further processing. Gene expression profiling was performed for whole

111 lungs of the other six animals per group by using microarrays.

\section{Determination of viral load}

113 Viral quantification was determined by plaque assay determining Plaque forming units (PFU)

114 following our laboratory standard operating procedures (Martínez-Orellana et al., 2015). Briefly,

115 supernatants were obtained after weighing, homogenizing and centrifuging lung samples. $0.1 \mathrm{ml}$

116 of 10-fold supernatant dilutions were incubated with MDCK cells plated in 12-well tissue

117 cultures plates for 1 hour. Then, cells were washed with phosphate buffer saline and plates were

118 overlaid with $1.4 \%$ noble agar (Becton Dickinson, France), mixed 1:1 with $0.5 \mu \mathrm{g} / \mathrm{ml}$ of bovine

119 trypsin and Minimum essential medium eagle (MEM) (both of Sigma-Aldrich SA, Madrid,

120 Spain) supplemented with $100 \mathrm{UI} / \mathrm{ml}$ penicillin and $100 \mathrm{ug} / \mathrm{ml}$ streptomycin (Invitrogen ${ }^{\circledR}$, 
121 Barcelona, Spain). After 4 days of incubation, cells were fixed for 20 min using 10\% formalin

122 (Sigma-Aldrich SA, Madrid, Spain) and then overlaid with 1\% crystal violet (Anorsa, Barcelona,

123 Spain). Finally, cells were washed with water in order to visualized plaques, which were counted

124 and compared to uninfected cells.

125 Histopathology

126 Lung samples were collected for macroscopical and histological examination according to our

127 laboratory standard operating procedures (Martínez-Orellana et al., 2015). The procedures

128 involved lung sample fixation using neutral-buffered $10 \%$ formalin for 48 hours, followed by

129 embedment in paraffin wax. Next, sections of $3 \mu \mathrm{m}$ were stained using haematoxylin and eosin

130 (HE). Cross sections of the lungs were analysed separately. A semi-quantitative assessment of

131 IAV-associated microscopic lesions in the lungs was performed for each animal. The lesional

132 scoring was graded on the basis of lesion severity as previously described by Vidaña et al

133 (Vidaña et al., 2014).

\section{RNA extraction and microarray processing and analyzing}

135 At designated time points (1, 5 and 10 dpi), C57BL6 mice were euthanized and lung tissue was

136 collected in RNA-later and stored at $-80^{\circ} \mathrm{C}$ until further processing. Total RNA was extracted

137 from lung samples using the Ribopure kit (Ambion, Life technology). RNA integrity and

138 concentration were evaluated as previously described (Almansa et al., 2015). A total amount of

$139100 \mathrm{ng}$ of mRNA was processed as described to obtain Cyanine 3-CTP-labeled cRNA (Almansa

140 et al., 2015). Next cRNA was hybridized with Mouse GE 4x44K v2 Microarray Kit (Agilent p/n

$141 \mathrm{G} 4846 \mathrm{~A})$ overnight (17hrs) at $65 \mathrm{C}$ on a rotator. Image acquisition was performed using an

142 Agilent Microarray Scanner (Agilent G2565CA) and data were extracted using the Agilent

143 Feature Extraction Software 10.7.1.1 following the Agilent protocol GE1-107_Sep09. Raw data 
144 were collected and preprocessed by using the GeneSpring GX 12.0 software (Almansa et al.,

145 2015). This software was employed also to perform the statistical analysis, which involved the

146 use of a moderate $\mathrm{T}$ test to identify those genes showing significant differences between their

147 expression levels fixing a $p$-value $<0.05$ with further application of the Benjamini-Hochberg

148 correction for multiple comparisons. A fold change in gene expression $\geq 2$ was used to obtain the

149 list of those genes showing the more important variations in their expression levels between

150 groups along time (1, 5 and $10 \mathrm{dpi}$ ). Ingenuity pathway analysis (IPA) (Ingenuity Systems-

151 Quiagen, Redwood City, CA) was employed to determine whether a canonical pathway is

152 enriched with genes of interest by using Fisher's exact test.

153 Microarray Data Accession Number.

154 Microarray expression data sets were uploaded at the Array Express microarray data repository 155 and are available publicly under accession number E-MTAB-3866.

\section{Validation of gene expression results from microarrays.}

157 Results of gene expression obtained using microarrays were confirmed by using a next 158 generation PCR technology, droplet digital PCR (ddPCR), using the Bio-Rad QX200 TM Droplet

159 Digital TM PCR system. 5ng of total mRNA were retro-transcribed to cDNA and analysed by 160 ddPCR using a Bio-Rad QX200 TM platform as previously described (Tamayo et al., 2014).

161 Quantification of expression levels of target mRNAs was performed using pre-designed 162 TaqMan ${ }^{\circledR}$ Assay Primer/Probe Sets, (FAM labelled MGB probes, Thermo Fisher/Scientific- Life

163 Technologies, Waltham, MA, USA): IL6 gene; interleukin 6 (Reference: Mm00446190_m1) and

164 IFNB1 gene; interferon beta 1 (Reference: Mm00439552_s1). The droplet reader used at least 16510000 droplets to determine the percentage of positive droplets and calculation of copy number 
166 of cDNA per ng of initial mRNA. Spearman correlation between ddPRC and microarrays results

167 was performed using SPSS 15.0. (Fig. S1).

168 Statistical analysis

169 SPSS 15.00 software was employed for perform statistical comparison of weight loss and viral

170 load between groups at all sampling times (SPSS Inc., Chicago, IL, USA). The statistical test

171 used was the U Mann-Whitney, and the significance level $(\alpha)$ was set at 0.05 . All graphs used for

172 represent the variations on weight loss and viral load were performed using GraphPad Prism 6

173 (GraphPad Software, La Jolla, CA, USA). 
175 Results

176 A (H1N1) pdm09 virus infection induced moderate weight loss during the first five days of

177 infection.

178 Weight was evaluated each day during the first 10 days following infection with the pandemic

179 CAT09 virus. Even though the percentage of body weight loss in CAT09-infected animals was

180 not dramatic, CAT09-infected mice showed significantly greater weight loss on the first five

181 days compared to uninfected controls $(\mathrm{p}<0.05)$. After $5 \mathrm{dpi}$, infected mice began to recover

182 their normal weight with no significant differences compared to mock mice (Figure 1a).

183 Human A (H1N1) pdm09 virus causes a productive infection in the lower respiratory tract of

184 mice.

185 Virus titers in lung homogenates measured on 1,5 and 10 dpi are shown in Figure $1 \mathrm{~b}(\mathrm{n}=6$ mice

186 per group). The highest value in viral load detected was one day after infection (average:

187 1.08E+05 PFU/g, SD: 1.43E+05). However, day 5 pi, infected animals were still secreting virus

188 in lungs [1.01E+04 PFU/g, 0.86E+04], becoming undetectable at day 10 p.i.

189 CAT09-infected mice developed pneumonia at day 5 post-infection, fully recovering at day 10

190 post infection.

191 Lung tissues from 6 animals per group were histopathologically examined at day 1, 5 and 10 pi.

192 As expected, control animals showed no histopathological lesions (Figure 2). Microscopic

193 lesional scores were assigned for each animal (Figure 2 B). At 1 dpi, three of six infected mice

194 presented histopathological lesions, two of them exhibited necrotizing bronchiolitis and the other

195 one presented bronchointerstitial pneumonia. At day 5 pi, five of six animals presented severe

196 bronchointerstitial pneumonia consisting of moderate to high numbers of lymphoplasmacytic

197 cells and neutrophils infiltrated the bronchiole and surrounding alveoli (Figure 2). Nevertheless, 
198 day 10 pi was characterized by the total resolution of lung lesions in the CAT09-infected

199 animals.

200 A (H1N1) pdm09 virus induced changes in gene expression levels in the lungs

201 Gene expression profiles (GEP) at lungs were compared between six infected animals and six

202 mock mice at days 1, 5 and 10 pi. No differences in GEP were found at day 1 pi (Figure 3a), but

203 important differences were observed at day 5 pi, paralleling the development of histological

204 pneumonia (Figure 3b and Table S1). In the CAT09-infected mice group, 1264 genes showed a

205 significant variation of their expression levels by day 5 pi compared to the control group (418

206 up-regulated and 847 down expressed) (Figure 3b and Table S1). Genes showing the most

207 important differences between both groups were interleukin 6 (IL6) (Fold change FC: 86.6),

208 interferon beta 1 (IFNb) (FC: 62.6) and chemokine (C-X-C motif) ligand 10 (IP10), (FC: 43.3)

209 (Figure 3 e,f and Table S1). Expression levels of the vast majority of genes normalized by day

210 10, coinciding with virus clearance and resolution of histological changes (Figure $3 \mathrm{c}$, e, $\mathrm{f}$ and

211 Table S1). Only 30 out of the 1264 genes kept on showing altered expression levels by day 10 p.i

212 (Figure S2 and Table S1). Interestingly, expression levels of IL6 persisted remarkably high by

213 this time point (FC:10.91) along with those of granzyme K (Gzmk) (FC:15.8) (Figure S2).

214 A (H1N1) pdm09 infection turned on the expression of genes involved in the innate response

215 and in the switch to adaptive immunity by day 5 pi.

216 Since most differences in gene expression were found by day 5 pi, we focused the Ingenuity

217 pathway analysis (IPA) on that day. The list of 1264 genes (either up and down regulated) was

218 analyzed by IPA in order to identify the canonical pathways that were enriched at day 5 pi.

219 Notably, Cellular immune response and Cytokine Signaling were the two signaling pathway 
220 categories more representative of our analysis (Table S2). The most significant canonical

221 pathways identify by IPA are describe in table 1 and figure $3 \mathrm{~d}$.

222 Most of these pathways were involved in the innate immune response and inflammation: [Role

223 of Hypercytokinemia/ hyperchemokinemia in the Pathogenesis of Influenza (Figure 4), Hepatic

224 Fibrosis/Hepatic Stellate Cell Activation, Agranulocyte Adhesion and Diapedesis, TREM1

225 Signaling, Differential Regulation of Cytokine Production in Intestinal Epithelial Cells by IL-

226 17A and IL-17F, Granulocyte Adhesion and Diapedesis, Altered T Cell and B Cell Signaling in

227 Rheumatoid Arthritis, Differential Regulation of Cytokine Production in Macrophages and T

228 Helper Cells by IL-17A and IL-17F, Role of IL-17F in Allergic Inflammatory Airway Diseases,

229 Graft-versus-Host Disease Signaling, Role of Macrophages, Fibroblasts and Endothelial Cells in

230 Rheumatoid Arthritis, Role of Pattern Recognition Receptors in Recognition of Bacteria and

231 Viruses and Wnt/ $\beta$-catenin Signaling pathway]. The vast majority of the genes involved in these

232 pathways coded for cytokines (Table S2). H1N1 virus also induced alterations in pathways

233 participating in the switch from innate to adaptive immunity: [Communication between Innate

234 and Adaptive Immune Cells, Crosstalk between Dendritic Cells and Natural Killer Cells, T

235 Helper Cell Differentiation]. Supplementary table S3 and figure 3 e,f show the variation of the

236 genes participating in these pathways along the study course. 


\section{Discussion}

240 The overarching aim of this work was to study the role of inflammation at pulmonary level

241 during a non-fatal infection caused by the 2009 pandemic influenza virus using the mice model.

242 In this sense, we analyzed the gene expression profiles (GEP) and its relation to histology and

243 viral dynamics in the lungs of healthy immune-competent mice with pneumonia caused by

244 human influenza A (H1N1) pdm09 virus.

245 Our GEP analysis allowed us to identify the presence of marked activation of innate immunity 246 genes by day 5post infection, paralleling the existence of extensive pneumonic/cellular infiltrates

247 in the lung, and active viral replication. The innate immune response is the first line of defence 248 against invading viruses (Iwasaki \& Pillai, 2014). Infection of the respiratory tract induced thus a

249 typical antiviral response characterised by the activation of pro-inflammatory cytokines and 250 interferon (IFNs) response genes (ISGs). In our analysis, the genes showing higher differences

251 for their expression levels between infected mice and controls were IL6, IFNb, and IP10. These 252 molecules, along with TNF and IL1b (also over-expressed at day 5), are the major cytokines 253 limiting viral replication during influenza infection, recruiting immune cells to the sites of 254 infection and producing inflammation (Nicholls, 2013).

255 IL6 is a pro-inflammatory cytokine which role in the pathogenesis of the A (H1N1) pdm09 256 remains unclear. There is a consensus in the literature about the existence of high systemic levels 257 of IL6 in severe patients infected by A (H1N1) pdm09 virus (Bermejo-Martin et al., 2009) (To et 258 al., 2010) (Zúñiga et al., 2011). This molecule induces pro-inflammatory responses such as 259 leukocyte recruitment into the lung. Excessive production of IL6 has been associated with 260 several pathological manifestations(Ho, Luo \& Lai, 2015) (Baillet et al., 2015). However, 261 Paquette et al demonstrated in IL6 deficient mice infected with A (H1N1) pdm09, that no 
262 significant differences in survival, weight loss, viral load, or pathology were observed between

263 IL6 deficient and wild-type mice following infection. Based in our results, presence of high

264 expression levels of this cytokine in the lung at day 10 could indicate that this cytokine plays a

265 role in viral clearance and tissue repair after pneumonia. Other mouse models support the idea of

266 a protective role of IL6 in influenza infections (Lauder et al., 2013).

267 IFNb is a cytokine member of type I interferon family. It induces an antiviral state in infected 268 and neighbouring cells (Ramos \& Fernandez-Sesma, 2015). To do so, IFNs induce the

269 transcription of hundreds of ISGs, which leads to numerous changes in the transcriptome of the

270 cell. Interestingly, in our analysis, some OAS genes (OAS1a, OAS1f, OASL1 and OAS2), IFIT

271 genes (IFIT1, IFIT2 and IFIT3), MX1, SOCS1 and CXCL10, all of them IGS genes, showed

272 high expression levels in the infected mice compared with controls. The antiviral interferon

273 response increased at day 5 pi. but decreased at day 10 pi. coinciding whit viral clearance. These

274 results are similar to the observations reported in previous studies using ferrets infected by A

275 (H1N1) pdm09 virus (León et al., 2013) (Rowe et al., 2010b). This authors showed an early

276 robust innate ISG and chemokine response that shut down on day 7-10 pi, when viral load was

277 undetectable.

278 The activation of a group of genes involved in the "Role of

279 hypercytokinemia/hyperchemokinemia in the Pathogenesis of Influenza" pathway, evidence the 280 existence of a local "cytokine storm" in the lung, following infection by A (H1N1) pdm09 virus.

281 Hypercytokinemia/hyperchemokinemia is a common finding that characterized an influenza

282 infection at transcriptomic level (Morrison et al., 2014), (Ma et al., 2011), (León et al., 2013),

283 (Rowe et al., 2010b) . Several experimental studies suggested that cytokine storm correlated 284 directly with tissue injury and an unfavorable prognosis of severe influenza (Liu, Zhou \& Yang, 
285 2016). In our study, concomitant with high expression levels of IL6, IFNb and ISGs, the virus

286 activated Th1 and chemokine responses mediated by IL1a, IL1b, IL12b,TNF, MCP1 and

287 RANTES. These results are similar to those found at systemic level in patients with primary viral

288 pneumonia (Bermejo-Martin et al., 2009) (Hagau et al., 2010) (To et al., 2010). In our model, the

289 marked inflammatory program observed by day 5 in the lung got deactivated by day 10 ,

290 paralleling resolution of histological changes and viral replication. Moreover, evaluation of gene

291 expression levels along time in the infected group confirmed the appearance of a strong pro-

292 inflammatory response at day 5 that is downmodulated at day 10 (Figure 3e,f and Supplementary

293 table S3). Similar results were also found in other experimental studies (Josset et al., 2012b),

294 (León et al., 2013), (Rowe et al., 2010b), where the decreased of cytokine expression levels

295 characterized the recovery phase of the disease. Therefore, a failure to effectively regulation of

296 excessive inflammation may be, in part, responsible for severe cases of 2009-H1N1.

297 In turn, the activation of genes involved in "Agranulocyte Adhesion and Diapedesis", "TREM1

298 Signaling", "Granulocyte Adhesion and Diapedesis", "Graft-versus-Host Disease Signaling and

299 "Role of Pattern Recognition Receptors in Recognition of Bacteria and Viruses" might confirm

300 the existence of a transcriptomic program aimed to recruit lymphocytes, monocytes and

301 neutrophils to the site of infection. Histological studies at day 5 pi confirmed the presence of

302 extensive pneumonic/cellular infiltrates into the lung. Although the primary role of the innate

303 immune response is limiting viral replication, excessive activation of innate immunity could

304 induce tissue damage (Vidaña et al., 2014) (de Jong et al., 2006). This phenomenon seems to

305 occur also in the context of autoimmunity diseases such as Rheumatoid Arthritis (Catrina et al.,

306 2016). In fact, "Altered T Cell and B Cell Signaling in Rheumatoid Arthritis" and "Role of

307 Macrophages, Fibroblasts and Endothelial Cells in Rheumatoid Arthritis" are two of the 
308 significant pathways identified by IPA in our analysis. In influenza disease, an exaggerated

309 inflammatory response has been cited as the cause of pulmonary oedema, alveolar haemorrhage

310 and acute respiratory distress syndrome, conditions associated with necrosis and tissue

311 destruction (To et al., 2001). Most of the genes participating in these pathways decreased their

312 expression levels on day 10 pi. paralleling resolution of pneumonia, reinforcing the idea that a

313 correct modulation of inflammatory response is essential for recovery in this disease.

314 IPA identified also three pathways related to interleukin 17: "Differential Regulation of Cytokine

315 Production in Intestinal Epithelial Cells by IL-17A and IL-17F, "Differential Regulation of

316 Cytokine Production in Macrophages and T Helper Cells by IL-17A and IL-17F and "Role of IL-

317 17F in Allergic Inflammatory Airway Diseases". Th-17 immunity participates in clearing

318 pathogens during host defence reactions but is involved also in tissue inflammation in several

319 autoimmune diseases, allergic diseases, and asthma (Nalbandian, Crispín \& Tsokos, 2009)

320 (Cheung, Wong \& Lam, 2008). In severe influenza it has been proposed to play a beneficial role

321 (Iwakura et al., 2008) (Bermejo-Martin et al., 2009) (Almansa et al., 2011b).

322 IPA also identified low expression levels of a group of genes involved in the "Wnt/ $\beta$-catenin

323 Signaling pathway" at 5 pi. It has been previously described that influenza virus down-regulates

324 the expression of proteins of this pathway like FZD (Shapira et al., 2009). This is consistent with

325 low expression levels of FZD2 and FZD7 genes found in our analysis. The biological

326 repercussion associated to down-modulation of this pathway remains to be elucidated.

327 Finally, the activation of those cytokine genes involved in the [Communication between Innate

328 and Adaptive Immune Cells, Crosstalk between Dendritic Cells and Natural Killer Cells, T

329 Helper Cell Differentiation] signalling pathways at day 5 pi. could be reflecting the development

330 of the adaptive immune response against the virus. Later 
331 activation of the adaptive immune response was previously supported by increased levels of

332 granzyme mRNAs in blood cells (Rowe et al., 2010a). In our study, the virus induced the

333 expression of granzyme A, B, and $\mathrm{K}$ at day 5 pi. Moreover, expression levels of gramzyme $\mathrm{K}$

334 persisted remarkably high at day $10 \mathrm{pi}$, which is consistent with the data published in ferret

335 infected by A (H1N1) pdm09 virus (Rowe et al., 2010a).

336 There are several works evaluating host transcriptomic responses to A (H1N1) pdm09 virus

337 using animal models (Powell \& Waters, 2017), with different scope, but not of all them properly

338 integrate the gene expression profiles induced by the infection with the pathogenic events to built

339 a comprehensive model to improve our understanding on the events underlying the appearance

340 and resolution of pneumonia caused by influenza (see table S4). The vast majority of these

341 experimental models have focused on studying the host immune responses to the virus only on

342 the acute phase of infection (Ma et al., 2011), (Camp et al., 2012), (Josset et al., 2012a), (Zou et

343 al., 2013), (Morrison et al., 2014). The present work studies the relationship between host

344 transcriptomic responses and the progression and resolution of infection caused by the A (H1N1)

345 pdm09 influenza virus. The most similar study to the one we present here is that published by

346 Rowe et al, 2010. In that paper, the authors employ ferrets, which is one of the best models to

347 reproduce human pathology in the context of influenza but, at the same time it is not an easily

348 available model, being expensive and complicated to manage. Our study employed a mouse

349 model, which is a more affordable, but nonetheless reproduced the major findings of Rowe et al,

350 who evidenced the existence of a exuberant cytokine and chemokines response at the lungs

351 paralleling histological changes, which was down-modulated following resolution of these

352 changes (Rowe et al., 2010b). Our results support thus the potential use of this mice model for

353 the study of immunopathology in influenza infection and for those works evaluating 
354 immunomodulators for the treatment of this disease. While other studies uses a mice adapted

355 influenza strain such as PR8 (Pommerenke et al., 2012) or other mouse passaged 2009 strains,

356 (Josset et al., 2012a), (Manchanda et al., 2016), our study employs a strain obtained directly form

357 a human patient. Mouse adaptation results in increased virulence and lung pathology and also

358 induces a strong host transcriptional response after infection compared with non adapted

359 influenza strains (Josset et al., 2012a). In our opinion, our model could help to better understand

360 the immune-pathogenic events on the basis of the most common scenario during the pandemics,

361 which was that corresponding to a non severe infection.

\section{Conclusions}

363 In conclusion, our findings suggest a dual role of pulmonary inflammation during non-fatal

364 infection caused by the 2009 pandemic influenza virus. On one side, the activation in the lung of

365 a marked innate immunity transcriptomic program was associated to the appearance of

366 pneumonia, but on the other hand, activation of this program paralleled viral clearance (Figure

367 5). Understanding the dynamics of the host's transcriptomic and virus changes over the course of

368 the infection caused by A (H1N1) pdm09 might help to identify the immune response profiles

369 associated to effective / balanced responses against influenza virus.

370

371 Acknowledgments:

372 The authors kindly thank to the BSL3 facility staff for the technical support they provided during

373 the experimental infection period. The authors are also grateful to Dr Tomas Pumarola's

374 laboratory from Hospital Clinic of Barcelona in Spain, for the generous gift of human pandemic

375 Influenza A virus, A/Catalonia/63/2009.

References: 
377 Almansa R., Anton A., Ramirez P., Martin-Loeches I., Banner D., Pumarola T., Xu L., Blanco J., 378 Ran L., Lopez-Campos G., Martin-Sanchez F., Socias L., Loza A., Andaluz D., Maravi E., 379 Gordón M., Gallegos MC., Fernandez V., León C., Merino P., Marcos MA., Gandía F., Bobillo 380 F., Resino S., Eiros JM., Castro C., Mateo P., Gonzalez-Rivera M., Rello J., de Lejarazu RO., 381 Kelvin DJ., Bermejo-Martin JF. 2011a. Direct association between pharyngeal viral secretion 382 and host cytokine response in severe pandemic influenza. BMC infectious diseases 11:232. DOI: 383 10.1186/1471-2334-11-232.

384

385

386

387

388

389

390

391

392

393

394

395

396

397

398

399

400

401

402

403

404

405

406

407

408

409

410

411

412

413

414

415

416

417

418

419

420

421

422

Almansa R., Bermejo-Martín JF., de Lejarazu Leonardo RO. 2012. Immunopathogenesis of 2009 pandemic influenza. Enfermedades Infecciosas Y Microbiología Clínica 30 Suppl 4:18-24. DOI: 10.1016/S0213-005X(12)70100-3.

Almansa R., Heredia-Rodríguez M., Gomez-Sanchez E., Andaluz-Ojeda D., Iglesias V., Rico L., Ortega A., Gomez-Pesquera E., Liu P., Aragón M., Eiros JM., Jiménez-Sousa MÁ., Resino S., Gómez-Herreras I., Bermejo-Martín JF., Tamayo E. 2015. Transcriptomic correlates of organ failure extent in sepsis. The Journal of Infection 70:445-456. DOI: 10.1016/j.jinf.2014.12.010.

Almansa R., Socias L., Ramirez P., Martin-Loeches I., Vallés J., Loza A., Rello J., Kelvin DJ., León C., Blanco J., Andaluz D., Micheloud D., Maraví E., Ortiz de Lejarazu R., Bermejo-Martin JF. 2011b. Imbalanced pro- and anti-Th17 responses (IL-17/granulocyte colony-stimulating factor) predict fatal outcome in 2009 pandemic influenza. Critical Care (London, England) 15:448. DOI: $10.1186 / \mathrm{cc} 10426$.

Baillet A., Gossec L., Paternotte S., Etcheto A., Combe B., Meyer O., Mariette X., Gottenberg JE., Dougados M. 2015. Evaluation of Serum Interleukin-6 Level as a Surrogate Marker of Synovial Inflammation and as a Factor of Structural Progression in Early Rheumatoid Arthritis: Results From a French National Multicenter Cohort. Arthritis Care \& Research 67:905-912. DOI: $10.1002 /$ acr.22513.

Bermejo-Martin JF., Martin-Loeches I., Rello J., Antón A., Almansa R., Xu L., Lopez-Campos G., Pumarola T., Ran L., Ramirez P., Banner D., Ng DC., Socias L., Loza A., Andaluz D., Maravi E., Gómez-Sánchez MJ., Gordón M., Gallegos MC., Fernandez V., Aldunate S., León C., Merino P., Blanco J., Martin-Sanchez F., Rico L., Varillas D., Iglesias V., Marcos MÁ., Gandía F., Bobillo F., Nogueira B., Rojo S., Resino S., Castro C., Ortiz de Lejarazu R., Kelvin D. 2010. Host adaptive immunity deficiency in severe pandemic influenza. Critical Care (London, England) 14:R167. DOI: 10.1186/cc9259.

Bermejo-Martin JF., Ortiz de Lejarazu R., Pumarola T., Rello J., Almansa R., Ramírez P., Martin-Loeches I., Varillas D., Gallegos MC., Serón C., Micheloud D., Gomez JM., TenorioAbreu A., Ramos MJ., Molina ML., Huidobro S., Sanchez E., Gordón M., Fernández V., Del Castillo A., Marcos MA., Villanueva B., López CJ., Rodríguez-Domínguez M., Galan J-C., Cantón R., Lietor A., Rojo S., Eiros JM., Hinojosa C., Gonzalez I., Torner N., Banner D., Leon A., Cuesta P., Rowe T., Kelvin DJ. 2009. Th1 and Th17 hypercytokinemia as early host response signature in severe pandemic influenza. Critical Care (London, England) 13:R201. DOI: $10.1186 / \mathrm{cc} 8208$. 
423 Busquets N., Segalés J., Córdoba L., Mussá T., Crisci E., Martín-Valls GE., Simon-Grifé M., 424 Pérez-Simó M., Pérez-Maíllo M., Núñez JI., Abad FX., Fraile L., Pina S., Majó N., Bensaid A., 425 Domingo M., Montoya M. 2010. Experimental infection with H1N1 European swine influenza 426 virus protects pigs from an infection with the 2009 pandemic H1N1 human influenza virus. 427 Veterinary Research 41:74. DOI: 10.1051/vetres/2010046.

428

429

430

431

432

433

434

435

436

437

438

439

440

441

442

443

444

445

446

447

448

449

450

451

452

453

454

455

456

457

458

459

460

461

462

463

464

465

466

467

468

Camp JV., Svensson TL., McBrayer A., Jonsson CB., Liljeström P., Bruder CE. 2012. De-novo transcriptome sequencing of a normalized cDNA pool from influenza infected ferrets. PloS One 7:e37104. DOI: 10.1371/journal.pone.0037104.

Catrina AI., Joshua V., Klareskog L., Malmström V. 2016. Mechanisms involved in triggering rheumatoid arthritis. Immunological Reviews 269:162-174. DOI: 10.1111/imr.12379.

Cheung PFY., Wong CK., Lam CWK. 2008. Molecular mechanisms of cytokine and chemokine release from eosinophils activated by IL-17A, IL-17F, and IL-23: implication for Th17 lymphocytes-mediated allergic inflammation. Journal of Immunology (Baltimore, Md.: 1950) 180:5625-5635.

Hagau N., Slavcovici A., Gonganau DN., Oltean S., Dirzu DS., Brezoszki ES., Maxim M., Ciuce C., Mlesnite M., Gavrus RL., Laslo C., Hagau R., Petrescu M., Studnicska DM. 2010. Clinical aspects and cytokine response in severe H1N1 influenza A virus infection. Critical Care (London, England) 14:R203. DOI: 10.1186/cc9324.

Health Protection Agency, Health Protection Scotland, National Public Health Service for Wales, HPA Northern Ireland Swine influenza investigation teams 2009. Epidemiology of new influenza A (H1N1) virus infection, United Kingdom, April-June 2009. Euro Surveillance:

Bulletin Européen Sur Les Maladies Transmissibles = European Communicable Disease Bulletin 14.

Ho L-J., Luo S-F., Lai J-H. 2015. Biological effects of interleukin-6: Clinical applications in autoimmune diseases and cancers. Biochemical Pharmacology 97:16-26. DOI: 10.1016/j.bcp.2015.06.009.

Itoh Y., Shinya K., Kiso M., Watanabe T., Sakoda Y., Hatta M., Muramoto Y., Tamura D., Sakai-Tagawa Y., Noda T., Sakabe S., Imai M., Hatta Y., Watanabe S., Li C., Yamada S., Fujii K., Murakami S., Imai H., Kakugawa S., Ito M., Takano R., Iwatsuki-Horimoto K., Shimojima M., Horimoto T., Goto H., Takahashi K., Makino A., Ishigaki H., Nakayama M., Okamatsu M., Takahashi K., Warshauer D., Shult PA., Saito R., Suzuki H., Furuta Y., Yamashita M., Mitamura K., Nakano K., Nakamura M., Brockman-Schneider R., Mitamura H., Yamazaki M., Sugaya N., Suresh M., Ozawa M., Neumann G., Gern J., Kida H., Ogasawara K., Kawaoka Y. 2009. In vitro and in vivo characterization of new swine-origin H1N1 influenza viruses. Nature 460:10211025. DOI: $10.1038 /$ nature 08260 .

Iwakura Y., Nakae S., Saijo S., Ishigame H. 2008. The roles of IL-17A in inflammatory immune responses and host defense against pathogens. Immunological Reviews 226:57-79. DOI: 10.1111/j.1600-065X.2008.00699.x. 
469 Iwasaki A., Pillai PS. 2014. Innate immunity to influenza virus infection. Nature Reviews.

470

471

472

473

474

475

476

477

478

479

480

481

482

483

484

485

486

487

488

489

490

491

492

493

494

495

496

497

498

499

500

501

502

503

504

505

506

507

508

509

510

511

512

513

514
Immunology 14:315-328. DOI: 10.1038/nri3665.

Jain S., Kamimoto L., Bramley AM., Schmitz AM., Benoit SR., Louie J., Sugerman DE., Druckenmiller JK., Ritger KA., Chugh R., Jasuja S., Deutscher M., Chen S., Walker JD., Duchin JS., Lett S., Soliva S., Wells EV., Swerdlow D., Uyeki TM., Fiore AE., Olsen SJ., Fry AM., Bridges CB., Finelli L., 2009 Pandemic Influenza A (H1N1) Virus Hospitalizations Investigation Team 2009. Hospitalized patients with 2009 H1N1 influenza in the United States, April-June 2009. The New England Journal of Medicine 361:1935-1944. DOI: 10.1056/NEJMoa0906695.

de Jong MD., Simmons CP., Thanh TT., Hien VM., Smith GJD., Chau TNB., Hoang DM., Van Vinh Chau N., Khanh TH., Dong VC., Qui PT., Van Cam B., Ha DQ., Guan Y., Peiris JSM., Chinh NT., Hien TT., Farrar J. 2006. Fatal outcome of human influenza A (H5N1) is associated with high viral load and hypercytokinemia. Nature Medicine 12:1203-1207. DOI: $10.1038 / \mathrm{nm} 1477$.

Josset L., Belser JA., Pantin-Jackwood MJ., Chang JH., Chang ST., Belisle SE., Tumpey TM., Katze MG. 2012a. Implication of inflammatory macrophages, nuclear receptors, and interferon regulatory factors in increased virulence of pandemic $2009 \mathrm{H} 1 \mathrm{~N} 1$ influenza A virus after host adaptation. Journal of Virology 86:7192-7206. DOI: 10.1128/JVI.00563-12.

Josset L., Engelmann F., Haberthur K., Kelly S., Park B., Kawoaka Y., García-Sastre A., Katze MG., Messaoudi I. 2012b. Increased viral loads and exacerbated innate host responses in aged macaques infected with the 2009 pandemic H1N1 influenza A virus. Journal of Virology 86:11115-11127. DOI: 10.1128/JVI.01571-12.

Lauder SN., Jones E., Smart K., Bloom A., Williams AS., Hindley JP., Ondondo B., Taylor PR., Clement M., Fielding C., Godkin AJ., Jones SA., Gallimore AM. 2013. Interleukin-6 limits influenza-induced inflammation and protects against fatal lung pathology. European Journal of Immunology 43:2613-2625. DOI: 10.1002/eji.201243018.

Lee N., Chan PKS., Hui DSC., Rainer TH., Wong E., Choi K-W., Lui GCY., Wong BCK., Wong RYK., Lam W-Y., Chu IMT., Lai RWM., Cockram CS., Sung JJY. 2009. Viral loads and duration of viral shedding in adult patients hospitalized with influenza. The Journal of Infectious Diseases 200:492-500. DOI: 10.1086/600383.

León AJ., Banner D., Xu L., Ran L., Peng Z., Yi K., Chen C., Xu F., Huang J., Zhao Z., Lin Z., Huang SHS., Fang Y., Kelvin AA., Ross TM., Farooqui A., Kelvin DJ. 2013. Sequencing, annotation, and characterization of the influenza ferret infectome. Journal of Virology 87:19571966. DOI: 10.1128/JVI.02476-12.

Liu Q., Zhou Y., Yang Z. 2016. The cytokine storm of severe influenza and development of immunomodulatory therapy. Cellular and Molecular Immunology 13:3-10. DOI: 10.1038/cmi.2015.74.

Ma W., Belisle SE., Mosier D., Li X., Stigger-Rosser E., Liu Q., Qiao C., Elder J., Webby R., 
515 Katze MG., Richt JA. 2011. 2009 pandemic H1N1 influenza virus causes disease and

516 upregulation of genes related to inflammatory and immune responses, cell death, and lipid

517 metabolism in pigs. Journal of Virology 85:11626-11637. DOI: 10.1128/JVI.05705-11.

518

519

520

521

522

523

524

525

526

527

528

529

530

531

532

533

534

535

536

537

538

539

540

541

542

543

544

545

546

547

548

549

550

551

552

553

554

555

556

557

558

559

560

Manchanda H., Seidel N., Blaess MF., Claus RA., Linde J., Slevogt H., Sauerbrei A., Guthke R., Schmidtke M. 2016. Differential Biphasic Transcriptional Host Response Associated with Coevolution of Hemagglutinin Quasispecies of Influenza A Virus. Frontiers in Microbiology 7:1167. DOI: $10.3389 /$ fmicb.2016.01167.

Martínez-Orellana P., Martorell J., Vidaña B., Majó N., Martínez J., Falcón A., RodríguezFrandsen A., Casas I., Pozo F., García-Migura L., García-Barreno B., Melero JA., Fraile L., Nieto A., Montoya M. 2015. Clinical response to pandemic $h 1 \mathrm{n} 1$ influenza virus from a fatal and mild case in ferrets. Virology Journal 12. DOI: 10.1186/s12985-015-0272-x.

Orellana-Martínez P. 2014. Analysis of host responses and fitness in different pandemic H1N1 (2009) influenza virus in mice and ferrets. Ph.D. Thesis. Universitat Autònoma de Barcelona.

Morrison J., Josset L., Tchitchek N., Chang J., Belser JA., Swayne DE., Pantin-Jackwood MJ., Tumpey TM., Katze MG. 2014. H7N9 and other pathogenic avian influenza viruses elicit a three-pronged transcriptomic signature that is reminiscent of 1918 influenza virus and is associated with lethal outcome in mice. Journal of Virology 88:10556-10568. DOI: 10.1128/JVI.00570-14.

Nalbandian A., Crispín JC., Tsokos GC. 2009. Interleukin-17 and systemic lupus erythematosus: current concepts. Clinical and Experimental Immunology 157:209-215. DOI: 10.1111/j.13652249.2009.03944.x.

Nicholls JM. 2013. The battle between influenza and the innate immune response in the human respiratory tract. Infection \& Chemotherapy 45:11-21. DOI: 10.3947/ic.2013.45.1.11.

Pommerenke C., Wilk E., Srivastava B., Schulze A., Novoselova N., Geffers R., Schughart K. 2012. Global transcriptome analysis in influenza-infected mouse lungs reveals the kinetics of innate and adaptive host immune responses. PloS One 7:e41169. DOI:

10.1371/journal.pone.0041169.

Powell JD., Waters KM. 2017. Influenza-Omics and the Host Response: Recent Advances and Future Prospects. Pathogens (Basel, Switzerland) 6. DOI: 10.3390/pathogens6020025.

Ramos I., Fernandez-Sesma A. 2015. Modulating the Innate Immune Response to Influenza A Virus: Potential Therapeutic Use of Anti-Inflammatory Drugs. Frontiers in Immunology 6:361. DOI: $10.3389 /$ fimmu.2015.00361.

Rowe T., Banner D., Farooqui A., Ng DCK., Kelvin AA., Rubino S., Huang SSH., Fang Y., Kelvin DJ. 2010a. In vivo ribavirin activity against severe pandemic H1N1 Influenza A/Mexico/4108/2009. The Journal of General Virology 91:2898-2906. DOI:

10.1099/vir.0.024323-0. 
561

562

563

564

565

566

567

568

569

570

571

572

573

574

575

576

577

578

579

580

581

582

583

584

585

586

587

588

589

590

591

592

593

594

595

596

597

598

599

600

601

602

603

604

605

606
Rowe T., León AJ., Crevar CJ., Carter DM., Xu L., Ran L., Fang Y., Cameron CM., Cameron MJ., Banner D., Ng DC., Ran R., Weirback HK., Wiley CA., Kelvin DJ., Ross TM. 2010 b. Modeling host responses in ferrets during A/California/07/2009 influenza infection. Virology 401:257-265. DOI: 10.1016/j.virol.2010.02.020.

Shapira SD., Gat-Viks I., Shum BOV., Dricot A., de Grace MM., Wu L., Gupta PB., Hao T., Silver SJ., Root DE., Hill DE., Regev A., Hacohen N. 2009. A Physical and Regulatory Map of Host-Influenza Interactions Reveals Pathways in H1N1 Infection. Cell 139:1255-1267. DOI: 10.1016/j.cell.2009.12.018.

Tamayo E., Almansa R., Carrasco E., Ávila-Alonso A., Rodríguez-Fernández A., Wain J., Heredia M., Gomez-Sanchez E., Soria S., Rico L., Iglesias V., Martínez-Martínez A., AndaluzOjeda D., Herreras JIG., Eiros JM., Bermejo-Martin JF. 2014. Quantification of IgM molecular response by droplet digital PCR as a potential tool for the early diagnosis of sepsis. Critical Care (London, England) 18:433. DOI: 10.1186/cc13910.

To KF., Chan PK., Chan KF., Lee WK., Lam WY., Wong KF., Tang NL., Tsang DN., Sung RY., Buckley TA., Tam JS., Cheng AF. 2001. Pathology of fatal human infection associated with avian influenza A H5N1 virus. Journal of Medical Virology 63:242-246.

To KKW., Hung IFN., Li IWS., Lee K-L., Koo C-K., Yan W-W., Liu R., Ho K-Y., Chu K-H., Watt C-L., Luk W-K., Lai K-Y., Chow F-L., Mok T., Buckley T., Chan JFW., Wong SSY., Zheng B., Chen H., Lau CCY., Tse H., Cheng VCC., Chan K-H., Yuen K-Y. 2010. Delayed clearance of viral load and marked cytokine activation in severe cases of pandemic H1N1 2009 influenza virus infection. Clinical Infectious Diseases: An Official Publication of the Infectious Diseases Society of America 50:850-859. DOI: 10.1086/650581.

Vemula SV., Zhao J., Liu J., Wang X., Biswas S., Hewlett I. 2016. Current Approaches for Diagnosis of Influenza Virus Infections in Humans. Viruses 8:96. DOI: 10.3390/v8040096.

Vidaña B., Martínez J., Martínez-Orellana P., García Migura L., Montoya M., Martorell J., Majó N. 2014. Heterogeneous pathological outcomes after experimental pH1N1 influenza infection in ferrets correlate with viral replication and host immune responses in the lung. Veterinary Research 45. DOI: 10.1186/s13567-014-0085-8.

Zou W., Chen D., Xiong M., Zhu J., Lin X., Wang L., Zhang J., Chen L., Zhang H., Chen H., Chen M., Jin M. 2013. Insights into the increasing virulence of the swine-origin pandemic H1N1/2009 influenza virus. Scientific Reports 3:1601. DOI: 10.1038/srep01601.

Zúñiga J., Torres M., Romo J., Torres D., Jiménez L., Ramírez G., Cruz A., Espinosa E., Herrera T., Buendía I., Ramírez-Venegas A., González Y., Bobadilla K., Hernández F., García J., Quiñones-Falconi F., Sada E., Manjarrez ME., Cabello C., Kawa S., Zlotnik A., Pardo A., Selman M. 2011. Inflammatory profiles in severe pneumonia associated with the pandemic influenza A/H1N1 virus isolated in Mexico City. Autoimmunity 44:562-570. DOI:

10.3109/08916934.2011.592885. 
607

608

609 Figure legends:

610 Figure 1: Changes in body weight and lung viral load induced by A (H1N1) pdm09 virus.

611 A) Average weight curve for C57BL6 mice infected through intranasal instillation with 50

613

614

615

616

617

618

619

620

621

622

623

624

625

626

627

628

629

630 $\mu \mathrm{L}$ CAT09 at $10^{4}$ PFU A/Catalonia/63/2009 (H1N1pdm) and mock.

B) Viral load in lung homogenates collected at days 1, 5 and 10 pi. (n=6 for all groups). Infection of Madin-Darby Canine Kidney cells was employed to measure viral titers.

The U Mann-Whitney test was used to compare weight loss and viral load between groups at all sampling time. The significance level $(\alpha)$ was set at 0.05 . Asterisks indicate significant differences between groups (A) or between times points (B).

\section{Figure 2: Histopathology of mice belonging to control and CAT09 groups at day 1, 5 and 10} pi.

A) Hematoxilin/Eosin stain. Arrows indicate the infiltrate in the viral infected lungs.

B) Microscopic lesional scores: grade 0 (no histopathological lesions observed), grade 1 (mild to moderate necrotising bronchiolitis), grade 2 (bronchointerstitial pneumonia characterised by necrotising bronchiolitis and diffuse alveolar damage in adjacent alveoli), and grade 3 (necrotising bronchiolitis and diffuse alveolar damage in the majority of the pulmonary parenchyma) (Vidaña et al., 2014).

Figure 3: Pulmonary gene expression profiles at day 1, 5 and 10 post infection.

$\mathrm{A}, \mathrm{B}, \mathrm{C})$ Volcano plots for the representation of the number of genes with significant variation of their expression levels between CAT09 and mock groups, at different time 
points (1 (A), 5 (B) and 10 (C) dpi). The level of significance was fixed in $p<0.05$, with Benjamini-Hochberg multiple testing corrections and Fold change $\geq 2$. The list of genes differentially expressed between groups is shown in table S1.

634 represents the percent of genes of each pathway whose expression levels were altered by the virus. Genes involved in the top 20 canonical signalling pathways are shown in table S2.

E, F) Gene expression levels of cytokines, chemokines (E) and IFN-stimulated genes (F) during infection with A (H1N1) pdm09 influenza virus. The heat map depicts the most representative immune response-related genes (yellow and blue coloured genes in Table

Table 1: Top 20 Canonical signaling pathways altered by A (H1N1)pdm 09 virus.

This table summarized the most significant canonical pathways identify by "Ingenuity pathway analysis". The IPA system implements Fisher's exact test to determine whether a canonical pathway is enriched with genes of interest (the level of significance was fixed in $p<0.05$ ). The ratio shows the number of genes whose expression levels were different between CAT09 and

652 mock groups, of the total of genes that have been described previously in each pathway. 653 
654 Figure 4: Role of Hypercytokinemia/hyperchemokinemia in the Pathogenesis of Influenza

655 signaling pathway.

656 "Ingenuity pathway analysis" identified this route as the most altered pathway of the analysis.

657 Red: genes up-regulated in the infected group compared with non-infected mice.

658

659 Figure 5: Model of uncomplicated A (H1N1) pdm09 viral infection:

660 The virus induced the activation of a marked pro-inflammatory program at the lung level

661 paralleling the emergence of histological changes. This program was associated to viral

662 clearance, and its resolution was accompanied by resolution of pneumonia.

663

664 Supplemental information:

665 Fig. S1: Droplet digital PCR validation of microarray data: Expression values obtained from

666 the microarrays for IFNB1 and IL6 genes showed a significant positive correlation, confirmed by

667 using digital droplet PCR.

668

669 Table S1: List of genes differentially expressed between infected mice and controls. FC: fold

670 change. Highlighted genes in colour represent genes involved in the top 20 canonical pathways

671 identified by IPA. Orange: represent cytokines or chemokines genes and blue represent

672 interferon stimulated genes. Red represents granzyme molecules.

673

674 Fig. S2: Pulmonary gene expression profiles at day 5 and 10 post infection

675

A) Venn diagram showing those genes whose expression levels differed from controls

676 either at day 5 and day 10, and those which differed only at one time point. 
677

678

679

680

681 682

683

684

685

686

687

688

689

690

691

692

693

694 695

B) Heatmap of the common signature across different time points. The colour is proportional to their fold change (FC) compared to mock group, with the scale ranging from $-4.2 \mathrm{FC}$ (blue) to $4.2 \mathrm{FC}$ (red).

Table S2: Genes involved in the top 20 canonical signalling pathways altered by A (H1N1) pdm 09 virus at day 5 post infection.

FC: fold change.

Table S3: Variation of gene expression along time in the infected group: Highlighted genes in colour represent genes involved in the top 20 canonical pathways identified by IPA. Orange: represent cytokines or chemokines genes and blue represent interferon stimulated genes. Red represents granzyme molecules.

Table S4: Studies evaluating host transcriptomic responses to A (H1N1) pdm09 influenza virus in animal models.

692 This table summarized the most significant previous studies evaluating the transcriptomic response to A (H1N1) pdm09 virus in different animal models.

$694 \mathrm{EID}_{50}: 50 \%$ Egg Infective Dose, $\mathrm{TCID}_{50}: 50 \%$ Tissue Culture Infective Dose, PFU: Plaque 695 Forming Unit, dpi: days post infection. 


\section{Figure 1}

Changes in body weight and lung viral load induced by A (H1N1) pdm09 virus.

A) Average weight curve for C57BL6 mice infected through intranasal instillation with $50 \mu \mathrm{L}$ CAT09 at10 4 PFU A/Catalonia/63/2009 (H1N1pdm) and mock.

B) Viral load in lung homogenates collected at days 1,5 and 10 pi. ( $n=6$ for all groups). Infection of Madin-Darby Canine Kidney cells was employed to measure viral titers.

The U Mann-Whitney test was used to compare weight loss and viral load between groups at all sampling time. The significance level $(\alpha)$ was set at 0.05 . Asterisks indicate significant differences between groups (A) or between times points (B).

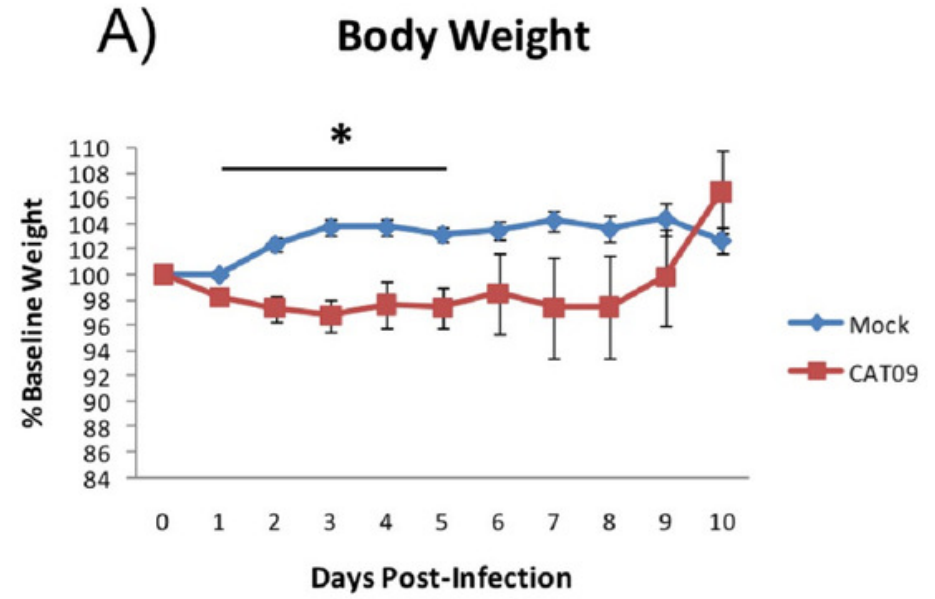

B) Lung viral load

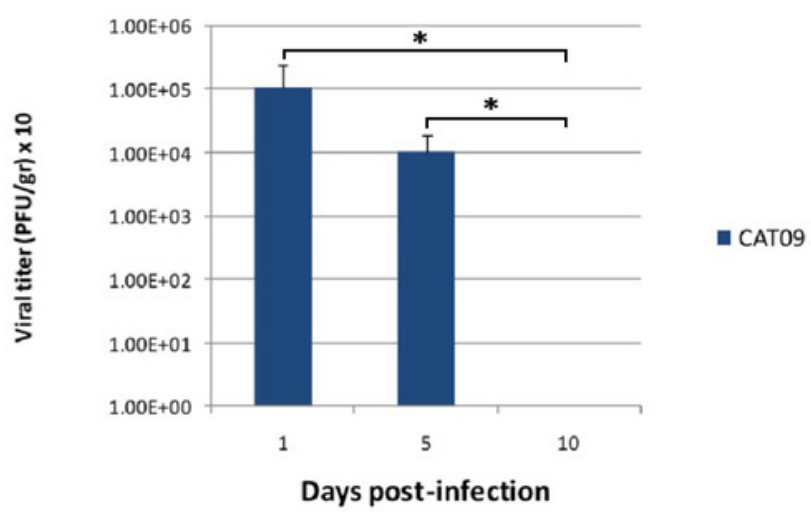


Figure 2

Histopathology of mice belonging to control and CAT09 groups at day 1, 5 and $10 \mathrm{pi}$.

A) Hematoxilin/Eosin stain. Arrows indicate the infiltrate in the viral infected lungs.

B) Microscopic lesional scores: grade 0 (no histopathological lesions observed), grade 1 (mild to moderate necrotising bronchiolitis), grade 2 (bronchointerstitial pneumonia characterised by necrotising bronchiolitis and diffuse alveolar damage in adjacent alveoli), and grade 3 (necrotising bronchiolitis and diffuse alveolar damage in the majority of the pulmonary parenchyma) (Vidaña et al., 2014) .

A)

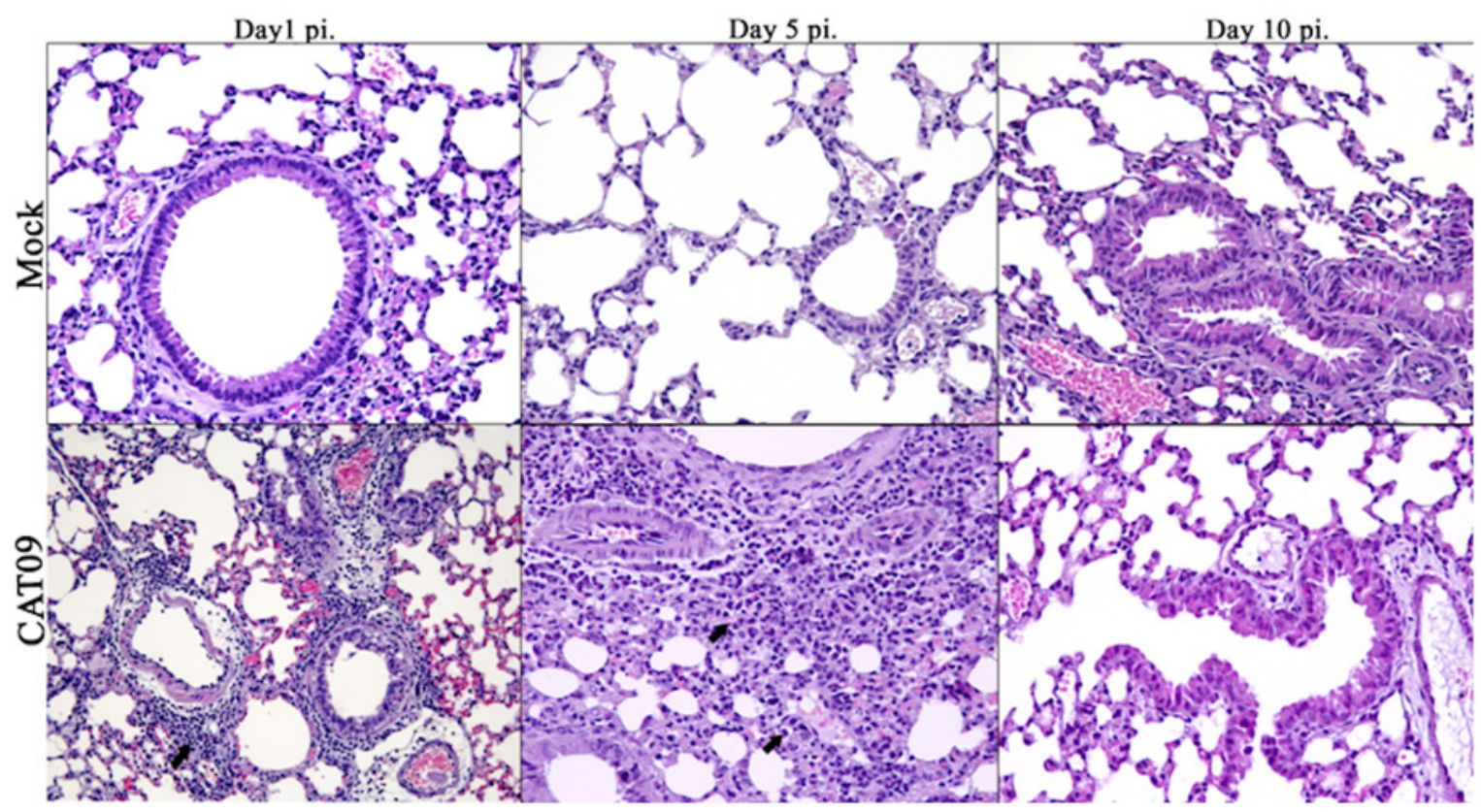

B)

\begin{tabular}{|c|c|c|c|c|c|c|}
\hline & \multirow{2}{*}{$\begin{array}{c}\text { Experimental } \\
\text { group }\end{array}$} & \multicolumn{4}{|c|}{ Hystological severity score } & \multirow[b]{2}{*}{ Average } \\
\hline & & 0 & 1 & 2 & 3 & \\
\hline \multirow[t]{2}{*}{ Day 1pi. } & Mock & 6 & & & & 0 \\
\hline & САТ09 & 3 & 2 & 1 & & 0,7 \\
\hline \multirow[t]{2}{*}{ Day 5 pi. } & Mock & 6 & & & & 0 \\
\hline & CAT09 & 1 & & 5 & & 1,7 \\
\hline \multirow[t]{2}{*}{ Day $10 \mathrm{pi}$. } & Mock & 6 & & & & 0 \\
\hline & САT09 & 6 & & & & 0 \\
\hline
\end{tabular}




\section{Figure 3}

\section{Pulmonary gene expression profiles at day 1,5 and 10 post infection.}

$A, B, C)$ Volcano plots for the representation of the number of genes with significant variation of their expression levels between CAT09 and mock groups, at different time points (1 (A), 5 (B) and 10 (C) dpi). The level of significance was fixed in $p<0.05$, with Benjamini-Hochberg multiple testing corrections and Fold change $>2$. The list of genes differentially expressed between groups is shown in table S1.

D) Top 20 Canonical signaling pathways altered by A (H1N1)pdm 09 virus. The x-axis represents the percent of genes of each pathway whose expression levels were altered by the virus. Genes involved in the top 20 canonical signalling pathways are shown in table S2.

E, F) Gene expression levels of cytokines, chemokines (E) and IFN-stimulated genes (F) during infection with A (H1N1) pdm09 influenza virus. The heat map depicts the most representative immune response-related genes (yellow and blue coloured genes in Table S3) that were differentially expressed between infection conditions at different time points. Colours represent the average value of gene expression levels of infected animals for each time point. 
A)

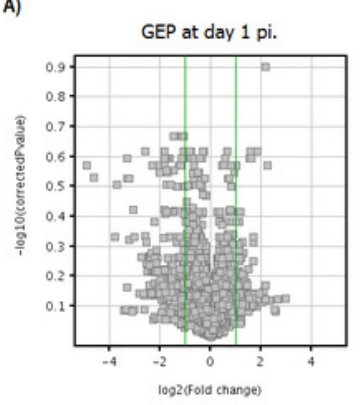

D)

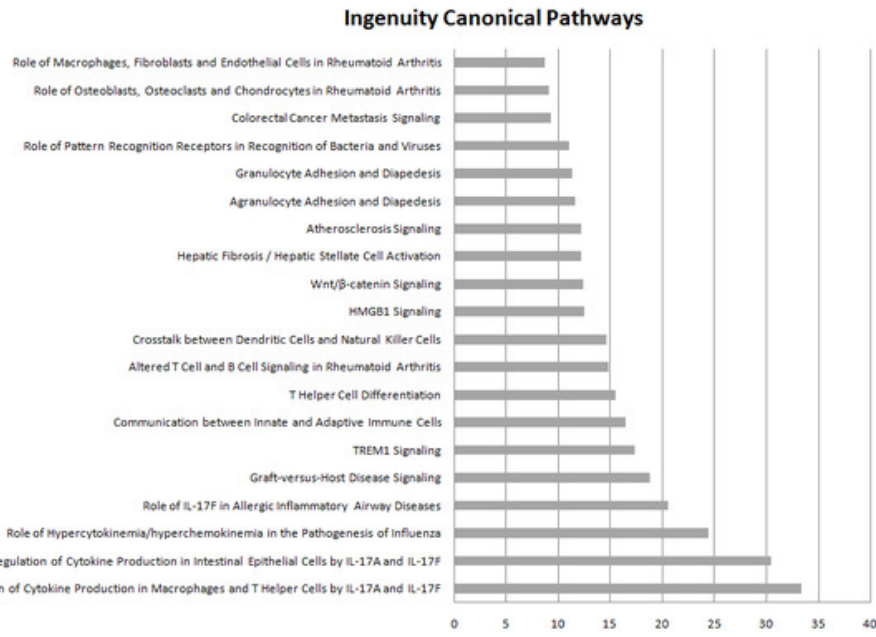

B)

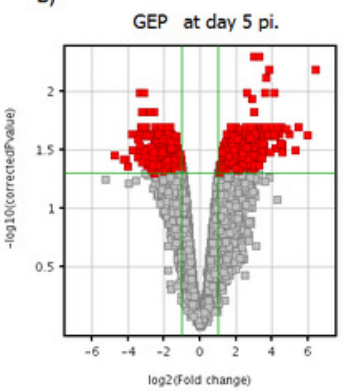

$\log 2$ (fold (hange)

E)

Cytokines \& Chemokines

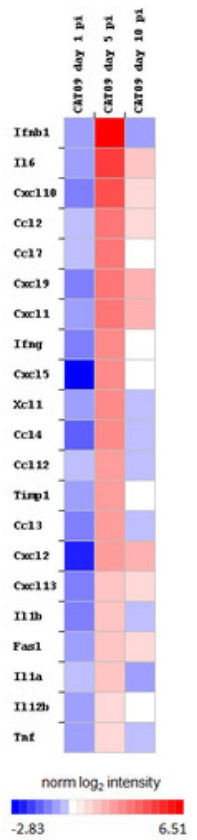

F)

ISGs

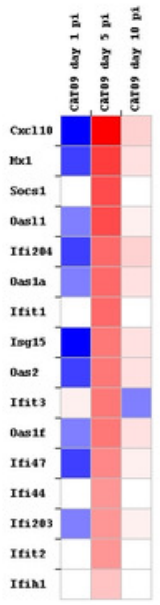

$\underbrace{\text { norm } \log _{2} \text { intensity }}_{-0.90}$ 


\section{Figure 4}

Role of Hypercytokinemia/hyperchemokinemia in the Pathogenesis of Influenza signaling pathway.

"Ingenuity pathway analysis" identified this route as the most altered pathway of the analysis. Red: genes up-regulated in the infected group compared with non-infected mice.

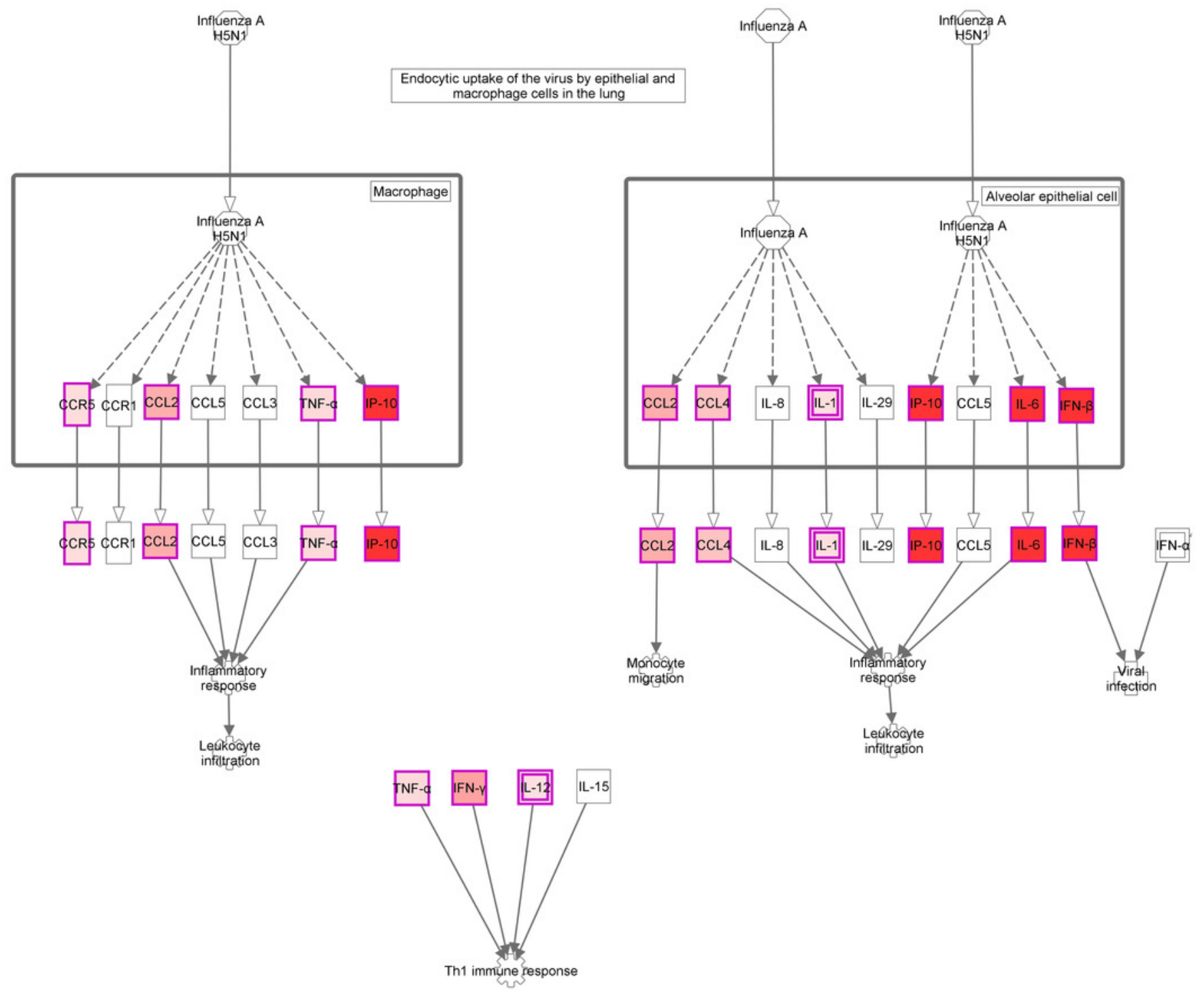


Figure 5

Model of uncomplicated A (H1N1) pdm09 viral infection

The virus induced the activation of a marked pro-inflammatory program at the lung level paralleling the emergence of histological changes. This program was associated to viral clearance, and its resolution was accompanied by resolution of pneumonia.

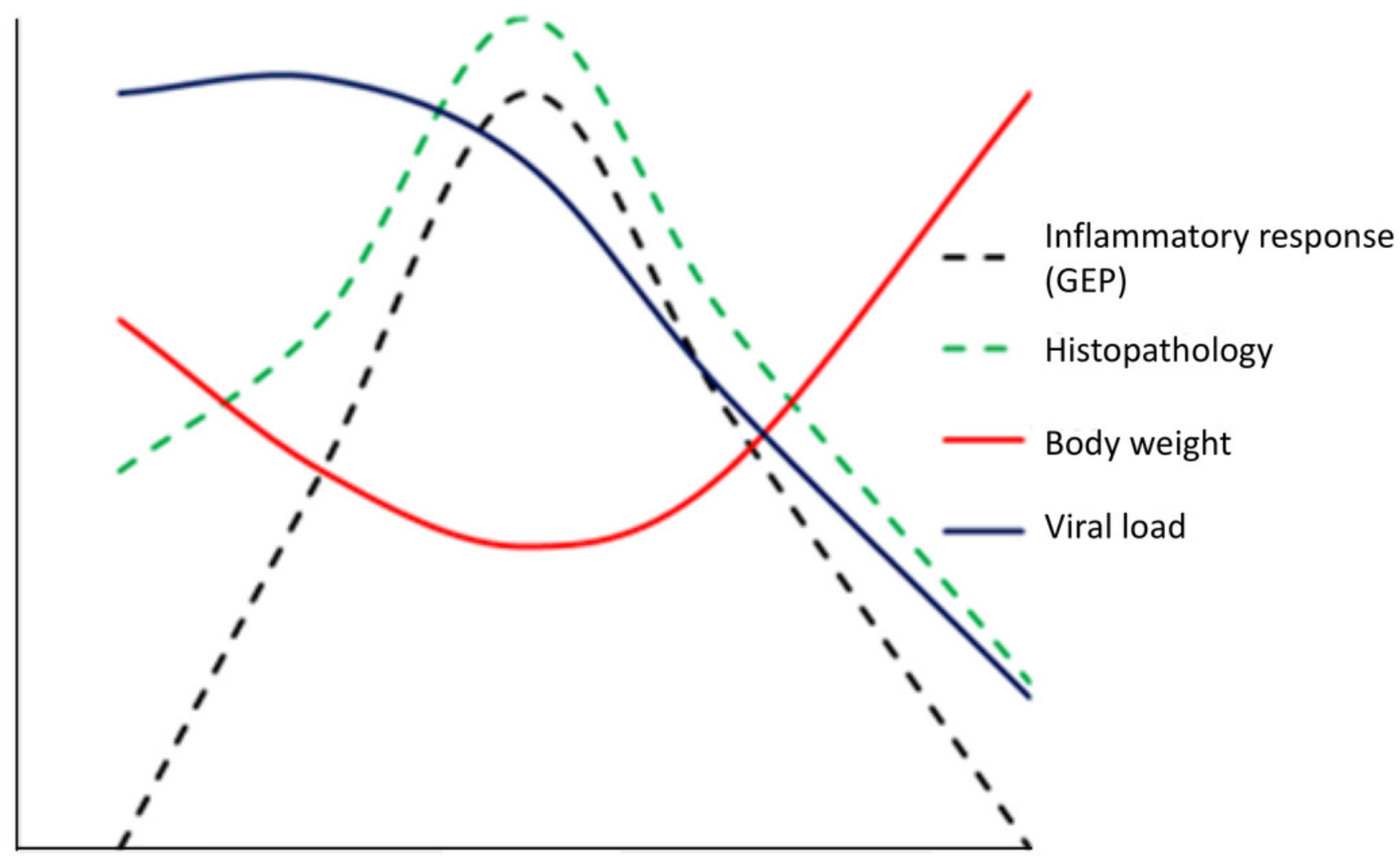

Day 1pi.

Day 5 pi.

Day 10pi. 


\section{Table $\mathbf{1}$ (on next page)}

Top 20 Canonical signaling pathways altered by A (H1N1)pdm 09 virus.

This table summarized the most significant canonical pathways identify by "Ingenuity pathway analysis". The IPA system implements Fisher's exact test to determine whether a canonical pathway is enriched with genes of interest (the level of significance was fixed in $p$ $<0.05$ ). The ratio show the number of genes whose expression levels were different between CAT09 and mock groups, of the total of genes that have been described previously in each pathway. 


\section{Top 20 Canonical signaling pathways altered by A (H1N1)pdm 09 virus}

\begin{tabular}{|c|c|c|c|}
\hline Ingenuity Canonical Pathways & p value & Ratio & Top Functions \& Diseases \\
\hline $\begin{array}{l}\text { Role of Hypercytokinemia/hyperchemokinemia in the Pathogenesis of } \\
\text { Influenza }\end{array}$ & $<0.001$ & 0.244 & $\begin{array}{l}\text { Cell-To-Cell Signaling and Interaction; Cellular Movement; Hematological System Development and } \\
\text { Function }\end{array}$ \\
\hline Hepatic Fibrosis / Hepatic Stellate Cell Activation & $<0.001$ & 0.122 & $\begin{array}{l}\text { Organismal Injury and Abnormalities; Cardiovascular System Development and Function; Organismal } \\
\text { Development }\end{array}$ \\
\hline Communication between Innate and Adaptive Immune Cells & $<0.001$ & 0.165 & $\begin{array}{l}\text { Cell-To-Cell Signaling and Interaction; Cellular Growth and Proliferation; Hematological System } \\
\text { Development and Function }\end{array}$ \\
\hline Wnt $/ \beta$-catenin Signaling & $<0.001$ & 0.124 & Gene Expression; Cellular Development; Tissue Development \\
\hline Agranulocyte Adhesion and Diapedesis & $<0.001$ & 0.116 & $\begin{array}{l}\text { Cell-To-Cell Signaling and Interaction; Tissue Development; Hematological System Development and } \\
\text { Function }\end{array}$ \\
\hline TREM1 Signaling & $<0.001$ & 0.173 & $\begin{array}{l}\text { Cell-To-Cell Signaling and Interaction; Hematological System Development and Function; Immune Cell } \\
\text { Trafficking }\end{array}$ \\
\hline $\begin{array}{l}\text { Differential Regulation of Cytokine Production in Intestinal Epithelial Cells } \\
\text { by IL-17A and IL-17F }\end{array}$ & $<0.001$ & 0.304 & $\begin{array}{l}\text { Cell-To-Cell Signaling and Interaction; Hematological System Development and Function; Immune Cell } \\
\text { Trafficking }\end{array}$ \\
\hline Granulocyte Adhesion and Diapedesis & $<0.001$ & 0.113 & $\begin{array}{l}\text { Cell-To-Cell Signaling and Interaction; Hematological System Development and Function; Immune Cell } \\
\text { Trafficking }\end{array}$ \\
\hline Altered T Cell and B Cell Signaling in Rheumatoid Arthritis & $<0.001$ & 0.148 & Hematological System Development and Function; Tissue Morphology; Cellular Development \\
\hline $\begin{array}{l}\text { Differential Regulation of Cytokine Production in Macrophages and T } \\
\text { Helper Cells by IL-17A and IL-17F }\end{array}$ & $<0.001$ & 0.333 & $\begin{array}{l}\text { Cell-To-Cell Signaling and Interaction; Hematological System Development and Function; Immune Cell } \\
\text { Trafficking }\end{array}$ \\
\hline Role of IL-17F in Allergic Inflammatory Airway Diseases & $<0.001$ & 0.205 & Connective Tissue Disorders; Immunological Disease; Inflammatory Disease \\
\hline Crosstalk between Dendritic Cells and Natural Killer Cells & $<0.001$ & 0.146 & $\begin{array}{l}\text { Cell-To-Cell Signaling and Interaction; Cellular Growth and Proliferation; Hematological System } \\
\text { Development and Function }\end{array}$ \\
\hline HMGB1 Signaling & $<0.001$ & 0.125 & $\begin{array}{l}\text { Cell-To-Cell Signaling and Interaction; Cellular Movement; Hematological System Development and } \\
\text { Function }\end{array}$ \\
\hline Graft-versus-Host Disease Signaling & $<0.001$ & 0.188 & Cellular Immune Response; Disease-Specific Pathways \\
\hline T Helper Cell Differentiation & $<0.001$ & 0.155 & Cell-mediated Immune Response; Cellular Development; Cellular Function and Maintenance \\
\hline Atherosclerosis Signaling & $<0.001$ & 0.122 & $\begin{array}{l}\text { Cell-To-Cell Signaling and Interaction; Cellular Movement; Hematological System Development and } \\
\text { Function }\end{array}$ \\
\hline $\begin{array}{l}\text { Role of Macrophages, Fibroblasts and Endothelial Cells in Rheumatoid } \\
\text { Arthritis }\end{array}$ & $<0.001$ & 0.087 & Cell Death and Survival; Cellular Development; Cellular Growth and Proliferation \\
\hline Colorectal Cancer Metastasis Signaling & $<0.001$ & 0.093 & Cell Death and Survival; Cell Cycle; Cellular Development \\
\hline Role of Osteoblasts, Osteoclasts and Chondrocytes in Rheumatoid Arthritis & 0.001 & 0.091 & Hematological System Development and Function; Tissue Morphology; Cellular Development \\
\hline $\begin{array}{l}\text { Role of Pattern Recognition Receptors in Recognition of Bacteria and } \\
\text { Viruses }\end{array}$ & 0.001 & 0.110 & Antimicrobial Response; Inflammatory Response; Infectious Disease \\
\hline
\end{tabular}

